\title{
CURRÍCULO E EDUCAÇÃO EM DIREITOS HUMANOS: DESAFIOS E POSSIBILIDADES
}

\author{
CURRICULUM AND EDUCATION ON HUMAN RIGHTS: CHALLENGES AND POSSIBILITIES
}

CURRÍCULO Y EDUCACIÓN EN DERECHOS HUMANOS: RETOS Y POSIBILIDADES

\author{
José Luis de Oliveira \\ Mestre e doutor em educação pela Pontifícia Universidade Católica do Paraná. Professor de graduação no \\ Centro Universitário Internacional Uninter. E-mail: joseluisctba@yahoo.com.br. \\ Orcid: https://orcid.org/0000-0003-2331-6684. \\ Eva Aparecida Oliveira \\ Assistente social pelo Centro Universitário UniBrasil. E-mail: evaoliveiractba@gmail.com. \\ Orcid: https://orcid.org/0000-0003-2537-3009; \\ Emily de Oliveira Abreu \\ Pedagoga pela Pontifícia Universidade Católica do Paraná. E-mail: emilydeoliveira_@hotmail.com. \\ Orcid: https://orcid.org/0000-0002-7092-0756
}

\begin{abstract}
RESUMO
Este artigo discute a política educacional brasileira diante dos desafios da contemporaneidade, para a efetivação de um modelo de educação que respeite a diversidade e a dignidade humana. Para tal, aborda a emergência da Educação em Direitos Humanos no processo de formação cidadã e no fortalecimento da democracia, ao problematizar sua relação com o currículo. O estudo discute o currículo, enquanto relação de poder, e enfatiza seu papel formativo, capaz de afetar a identidade dos estudantes, o que incide sobre suas ações e decisões. A questão da Educação em Direitos Humanos, que já era apontada como importante desde a Declaração dos Direitos Humanos em 1948, ganhou mais relevância na comunidade internacional com a promoção da Década da Educação em Direitos Humanos — ocorrida entre 1995 e 2004. Em sintonia com o cenário internacional, o governo brasileiro criou, em 2003, o Comitê Nacional de Educação em Direitos Humanos, com a atribuição de elaborar e monitorar o Plano Nacional de Educação em Direitos Humanos (PNEDH), que após ser objeto de vários debates e modificações ao longo dos anos, chega à sua versão definitiva em 2007. Tais avanços são indícios daquilo que o Brasil vem construindo na defesa de uma sociedade mais democrática, justa e solidária.
\end{abstract}

Palavras-chave: Educação em Direitos Humanos. Currículo. Plano Nacional de educação em Direitos Humanos. Diretrizes Nacionais para a educação em Direitos Humanos.

\begin{abstract}
This article discusses the Brazilian educational policy in the face of contemporary challenges for implementing an education model that respects diversity and human dignity. To this end, it addresses the emergence of Human Rights Education in the process of citizen formation and the strengthening of democracy, problematizing its relationship with the curriculum. It discusses the curriculum, as a power relationship, emphasizing its formative role capable of affecting the students' identity, focusing on their actions and decisions. The issue of Education in Human Rights, which was already pointed out as important since the Declaration of Human Rights in 1948, gained more relevance in the international community with the promotion of the Decade of Education in Human Rights — which occurred between 1995 and 2004. In line with the international scenario, the Brazilian government created, in 2003, the National Human Rights Education Committee with the attribution of elaborate and monitor the National Human Rights Education Plan (PNEDH), which, after being the subject of several debates and changes over the years, reached its final
\end{abstract}


version in 2007. Such advances are shreds of evidence to what Brazil has been building in defense of a more democratic, just, and solidary society.

Keywords: Human Rights education. Curriculum. National Human Rights education Plan. National Guidelines for Human Rights education.

\section{RESUMEN}

Este artículo analiza la política educativa brasileña frente a los desafíos contemporáneos para la realización de un modelo educativo que respete la diversidad y la dignidad humana. Para ello, aborda el surgimiento de la Educación en Derechos Humanos en el proceso de formación ciudadana y el fortalecimiento de la democracia, problematizando su relación con el currículo. Discute el currículo, como relación de poder y enfatiza su rol formativo, capaz de incidir en la identidad de los estudiantes, lo que incide sobre sus acciones y decisiones. El tema de la Educación en Derechos Humanos, que ya se señalaba como importante desde la Declaración de Derechos Humanos de 1948, cobró mayor relevancia en la comunidad internacional con la promoción de la Década de la Educación en Derechos Humanos, ocurrida en el período 1995-2004. En línea con el escenario internacional, el gobierno brasileño, en 2003, creó el Comité Nacional de Educación en Derechos Humanos, con la atribución de elaborar y darle seguimiento al Plan Nacional de Educación en Derechos Humanos (PNEDH), que, luego de ser objeto de varios debates y cambios a lo largo de los años, llegó a su versión final en 2007. Tales adelantos son indicios de lo que Brasil viene construyendo en defensa de una sociedad más democrática, justa y solidaria.

Palabras-clave: Educación en Derechos Humanos. Reanudar. Plan Nacional de Educación en Derechos Humanos. Directrices Nacionales para la educación en Derechos Humanos.

\section{INTRODUÇÃO}

O propósito deste texto, de abordagem qualitativa, é discutir a temática da Educação em Direitos Humanos (EDH), ao considerar sua relação com o currículo escolar. Ele se soma ao esforço empreendido por várias pessoas e entidades em prol da efetivação do Plano Nacional de Educação em Direitos Humanos (PNEDH), como estratégia coletiva na construção de projetos que possibilitem a defesa, promoção e a vivência dos direitos humanos.

Devido sua grande relevância, a cada dia tem se ampliado mais as discussões envolvendo o tópico Educação em Direitos Humanos. Mundialmente, a questão ganhou mais visibilidade com a promulgação por parte da Organização das Nações Unidas (ONU) da Década da Educação em Direitos Humanos, ocorrida entre 1995 e 2004. Consoante com o cenário internacional, o governo brasileiro criou, em 2003, o Comitê Nacional de Educação em Direitos Humanos (CNEDH), o que iniciou o processo de elaboração do PNEDH, o qual teve sua primeira versão lançada em dezembro daquele ano.

A Educação em Direitos Humanos é vista no PNEDH de forma abrangente, como um eixo fundamental da educação básica, da educação superior, dos profissionais de mídia, segurança e justiça. Trata-se de um modelo de educação voltada para o respeito e 
valorização da diversidade, aos conceitos de sustentabilidade e de formação da cidadania ativa que deve "permear o currículo, a formação inicial e continuada dos profissionais da educação, o projeto político-pedagógico da escola, os materiais didático-pedagógicos, o modelo de gestão e a avaliação." (BRASIL, 2007, p. 32).

Nesse sentido, a instituição escolar precisa ser compreendida não apenas como o espaço/tempo em que se realiza a construção do conhecimento, mas, muito além, deve ser pensada como um espaço/tempo que capacite os estudantes para refletir e analisar criticamente a sociedade da qual fazem parte, preparando-os para intervir nela, pois conforme ressalta Torres Santomé (2013, p. 79), “todo sistema educacional tem, entre suas finalidades, colaborar para construir identidades dos meninos e meninas". Segundo o pesquisador, identidade são "aqueles conhecimentos, procedimentos, habilidades e valores que cada pessoa aprende, desenvolve e põe em funcionalidade para compreender, avaliar e interferir no mundo".

No entanto, como nos adverte Eyng (2013, p. 46), “o contexto escolar ainda está muito marcado por discursos culturais do capitalismo", os quais, segundo a autora, “[...] definem contextos e enredam os sujeitos, incidem sobre suas decisões e ações, afetando a formação das identidades e a qualidade da convivência na sociedade e nas escolas [...]”. Uma educação centrada nos direitos humanos visa justamente à desconstrução desta realidade e a construção de uma nova, onde "[...] o espaço escolar seja caracterizado pela garantia, proteção e vivencia de direitos, com superação da violação de direitos, evidente nas diversas faces das violências nas escolas [...]”.

Neste contexto e considerando que os currículos educacionais definem os saberes e conhecimentos que serão ou não desenvolvidos e valorizados, a inserção da EDH nesse documento pode contribuir de fato e de forma marcante na condução e promoção do desenvolvimento de uma cultura de humanização na escola. Em meio às realidades marcadas pela exclusão e pelas sistemáticas violações dos direitos fundamentais dos indivíduos e dos grupos, a garantia de sucesso na educação se efetivará com a "[...] adoção de narrativas curriculares capazes de configurar processos formativos pautados na garantia, proteção e vivência dos direitos individuais e coletivos, dos quais resultem traços identitários mais solidários" (EYNG, 2013, p. 46).

Ao considerar o que foi posto, este artigo, de abordagem bibliográfica e qualitativa, objetiva colaborar com a discussão a respeito da EDH; o intuito é refletir a política 
educacional brasileira diante dos desafios da contemporaneidade, para a efetivação de uma educação que respeite a diversidade e a dignidade humana.

Para tal, adotamos a estratégia de fazer, incialmente, uma rápida aproximação conceitual sobre o objeto, o fundamento e a natureza da Educação em Direitos Humanos e sua inserção no cenário internacional e brasileiro. Em seguida, problematizamos o currículo escolar como território de disputas e espaço de garantia de direitos, abordando as concepções conservadoras e transformadoras nas quais as políticas e práticas educacionais se firmam.

\section{Teorias do currículo: diferentes concepções}

O conceito de currículo é polissêmico e, em decorrência dos diversos modos de como a educação foi sendo historicamente concebida, ele recebeu diferentes abordagens em relação ao seu significado e atribuições. Conforme Silva (2011, p. 14), “[...] uma definição de currículo não nos revela o que é, essencialmente o currículo", mas, apenas “[...] nos revela o que uma determinada teoria pensa o que o currículo é”. Nesse sentido, o pesquisador ressalta que "talvez mais importante e mais interessante do que a busca de definição última de ‘currículo’ seja a de saber quais questões uma ‘teoria’ do currículo ou um discurso curricular busca responder." (SILVA, 2011, p. 14).

Inicialmente, o conceito de currículo limitava-se ao que conhecemos como "grade/matriz curricular”, que seria a organização das matérias/disciplinas obedecendo a um determinado tempo e lugar dentro da escola. Todavia, conforme indica Eyng (2012, p. 13-14), o currículo vai muito além do que o conjunto de disciplinas ou a seleção sequenciada delas, na verdade, “[...] é tudo isso em interação com os sujeitos sociais e históricos que nele projetam seus anseios e interesses e lhe dão vida e significado".

De acordo com Silva (2011, p. 12), os primeiros estudos sobre o currículo apareceram nos Estados Unidos nos anos XX, com o lançamento da obra de Franklin Bobbitt intitulada The Curriculum. Posteriormente, os reflexos da influência norte-americana alcançaram o contexto brasileiro e, de acordo com Oliveira (2008, p. 536), a primeira publicação sobre o tema no cenário nacional foi a obra Introdução ao Estudo do Currículo da Escola Primária, de João Roberto Moreira em 1955. Mais adiante, já na década de 1970, o termo currículo passou a fazer parte da Lei de Diretrizes e Bases $n^{\circ} 5.692$. 
A etimologia do termo remete à ideia de caminho, percurso, algo que vai adiante, que tem ligação com um momento histórico e que parte de uma construção social. Nesse sentido, Moreira e Silva (2002, p. 7), ressaltam que “[...] o currículo é considerado um artefato social e cultural" e, desse modo, deve ser compreendido como um campo permeado por ideologia, cultura e relações de poder.

Nesse sentido, percebe-se que a questão central que envolve as diferentes e diversas teorias do currículo diz respeito a sabermos a qual projeto cultural queremos que a educação sirva e, nesse embate, decidir qual conhecimento deve ser ensinado, qual é válido ou importante a ponto de fazer parte do currículo. Assim "o currículo é sempre parte o resultado de uma seleção: de um universo mais amplo de conhecimentos e saberes seleciona-se aquela parte que vai construir, precisamente o currículo." (SILVA, 2011, p. 15).

Desde seu surgimento, tanto a escola quanto a educação escolarizada são marcadas por finalidades bem específicas que ultrapassam o âmbito da transmissão desinteressada da cultura; pelo contrário, mantiveram-se sempre vinculadas aos projetos e requerimentos que atendiam às necessidades da classe hegemônica de cada momento, assim como de um tipo específico de sociedade, a determinados modelos de vida e a uma certa hierarquia de valores.

É no bojo desse embate entre sujeitos e culturas que o currículo ganha relevância. Desse modo, ao pensarmos no projeto educacional, fica evidente que este caminho sempre será orientado por um grupo, o qual fará a seleção, de acordo com seus critérios e interesses, dos conhecimentos a serem ensinados. Quanto a isso, Moreira e Silva (2002, p. 8) esclarecem que:

O currículo não é um elemento inocente e neutro de transmissão desinteressada do conhecimento social. O currículo está implicado em relações de poder, o currículo transmite visões sociais particulares e interessadas, o currículo produz identidades individuais e sociais particulares. O currículo não é um elemento transcendente e atemporal - ele tem uma história, vinculada a formas específicas e contingentes de organização da sociedade e da educação.

Percebe-se, então, que o currículo não é imparcial, ou como diria Moreira e Silva (2002, p. 28), ele “[...] não é o veículo de algo a ser transmitido e passivamente absorvido, mas o terreno em que ativamente se criará e produzirá cultura". Corroborando, Apple (2002, p. 59) ressalta que

O currículo nunca é apenas um conjunto neutro de conhecimentos, que de algum modo aparece nos textos e nas salas de aula de uma nação. Ele é sempre parte de uma tradição seletiva, resultado de uma seleção de alguém, da visão de algum 
grupo acerca do que seja conhecimento legítimo. É produto de tensões, conflitos e concessões culturais, políticas e econômicas que organizam e desorganizam um povo.

Em sua trajetória histórica, o currículo sofreu influências de diversas correntes pedagógicas e foi objeto de estudo de autores de vertentes ideológicas bastante distintas, o que levou a diversas teorias a respeito dele. Desse modo, quanto ao âmbito conceitual sobre currículo, as concepções diferem-se em teorizações tradicionais, críticas e póscríticas, as quais operam diferentes pressupostos, a partir dos quais podem ser planejadas trajetórias formativas diversas.

Uma melhor compreensão das implicações de cada uma dessas teorias nas práticas desenvolvidas pelas escolas e nas salas de aula é apresentada por Eyng (2012, p. 36-37), conforme Quadro 1.

QUADRO 1 - Teorias Curriculares

\begin{tabular}{|c|c|c|}
\hline TEORIA DE CURRÍCULO & CONCEITOS FUNDAMENTAIS & CONCEPÇÕES CURRICULARES \\
\hline TRADICIONAIS & $\begin{array}{l}\text { Ensino, aprendizagem, avaliação, } \\
\text { metodologia, didática, organização, } \\
\text { planejamento, eficiência, objetivos. }\end{array}$ & $\begin{array}{l}\text { Modelo curriculares hegemônicos e } \\
\text { supostamente neutros. Currículos } \\
\text { entendidos como normatização, } \\
\text { prescrição, centrados nos conteúdos } \\
\text { disciplinares e/ou listas de objetivos. } \\
\text { Esses modelos difundiram a ideia de } \\
\text { currículo como equivalente a grade } \\
\text { curricular. }\end{array}$ \\
\hline CRÍTICAS & $\begin{array}{l}\text { Ideologia, reprodução cultural e social, } \\
\text { poder, classe social, capitalismo, } \\
\text { relações sociais de produção, } \\
\text { conscientização, emancipação e } \\
\text { libertação, currículo oculto e } \\
\text { resistência. }\end{array}$ & $\begin{array}{l}\text { Os currículos são ideologicamente } \\
\text { situados. Currículos entendidos como } \\
\text { inseridos nas relações de poder, } \\
\text { especialmente nos interesses das } \\
\text { lutas de classe. Assim, o currículo se } \\
\text { converte em espaço de resistência, } \\
\text { como forma de libertação da } \\
\text { opressão econômico-capitalista e } \\
\text { possibilidade de emancipação. }\end{array}$ \\
\hline PÓS-CRÍTICAS & $\begin{array}{l}\text { Identidade, alteridade, diferença, } \\
\text { subjetividade, significação e discurso, } \\
\text { saber-poder, representação, cultura, } \\
\text { gênero, raça, etnia, sexualidade, } \\
\text { multiculturalismo. }\end{array}$ & $\begin{array}{l}\text { Os currículos são práticas de } \\
\text { subjetivação, de significação e } \\
\text { discurso produzidos nas relações de } 4 \\
\text { saber-poder. Currículos entendidos } \\
\text { como formas de seleção e } \\
\text { representação da cultura, } \\
\text { compreendendo as questões de } \\
\text { gênero, raça, etnia, sexualidade, } \\
\text { multiculturalismo. }\end{array}$ \\
\hline
\end{tabular}

Fonte: Eyng (2012).

Em relação à teoria tradicional de currículo, Silva (2011) salienta que esta entende que o funcionamento da escola deveria seguir os parâmetros industriais, ou seja, basear-se na eficiência, produtividade, organização, caráter técnico e que os resultados pretendidos 
estivessem bem especificados e quais os métodos seriam utilizados para alcançá-los. Entre os principais representantes desta teoria, o autor destaca Franklin Bobbitt e sua obra The Curriculum de 1918, considerada o marco no estabelecimento do currículo como um campo especializado de estudos. Nessa perspectiva, Silva (2011, p.12) destaca que "o currículo é visto como um processo de racionalização de resultados educacionais, cuidadosa e rigorosamente especificados e medidos. O modelo institucional dessa concepção de currículo é a fábrica".

Segundo o autor, partindo de uma adaptação dos novos conceitos da administração industrial para a escola, nessa perspectiva tradicional o currículo resume-se a uma atividade burocrática, uma questão técnica.

Posteriormente, Silva (2011, p. 29), ressalta que na década de 1960, em decorrência das transformações oriundas dos movimentos sociais e culturais "[...] surgiram livros, ensaios, teorizações que colocavam em xeque o pensamento e a estrutura educacional tradicionais". O autor destaca que no bojo dessas mudanças e baseadas em conceitos marxistas, nascem as teorias críticas do currículo, as quais questionavam as estruturas sociais vigentes e traziam a reflexão sobre as desigualdades sociais. A preocupação de tais teorias fugia à simples construção do currículo e se prendia mais no que ele podia fazer. Nesse sentido:

Os modelos tradicionais de currículo restringiam-se à atividade técnica de como fazer o currículo. As teorias críticas sobre o currículo, em contraste, começam por colocar em questão precisamente os pressupostos dos presentes arranjos sociais e educacionais. As teorias críticas desconfiam do status quo, responsabilizando-o pelas desigualdades e injustiças sociais. As teorias tradicionais eram teorias de aceitação, ajuste e adaptação. As teorias críticas são teorias de desconfiança, questionamento e transformação radical (SILVA, 2011, p. 30).

Neste cenário, ganham destaque certos pensadores como o filósofo francês Louis Althusser (1918-1990), Pierre Félix Bourdieu (1930-2002) e Jean-Claude Passeron. Conforme Silva (2011, p. 34), Althusser, partindo de uma análise marxista, defendia que “[...] a escola contribui para a reprodução da sociedade capitalista ao transmitir, através das matérias escolares, as crenças que nos fazem ver os arranjos sociais existentes como bons e desejáveis". Pela mesma vertente, porém contrariamente à análise marxista defendida por Althusser, os pensadores Bourdieu e Passeron ressaltam que na verdade "[...] a dinâmica da reprodução social está centrada no processo de reprodução cultural. É através da reprodução da cultura dominante que a reprodução mais ampla da sociedade fica 
garantida [...]". Ainda na linha das teorias do currículo de base crítica, Silva (2011) ressalta outros pensadores que aparecem como precursores de novos conceitos sobre o currículo. Por exemplo, Michael Apple defende que o currículo atendia aos interesses das classes dominantes, visto que a seleção de seus conteúdos impunha suas verdades. Já nas análises do americano Henry Giroux, as teorias tradicionais de currículo, por não considerarem o caráter histórico, político, cultural e social do currículo, acabavam contribuindo para a reprodução das desigualdades e das injustiças sociais. No Brasil, Paulo Freire (1921-1997) sintetiza sua crítica ao currículo existente a partir do conceito de "educação bancária", aquela que concebe o conhecimento simplesmente como algo a ser transferido para o aluno.

Mais recentemente, frente a um contexto pós-moderno caracterizado pela diversidade das formas culturais do mundo contemporâneo, surge a teoria pós-crítica. Tal teoria não se prende apenas nos debates concernentes à relação de poder entre as classes sociais e avança nas análises sobre a conexão entre currículo e multiculturalismo, questões sociais e de gênero. Nesse sentido, amplia os conceitos da teoria crítica, uma vez que de acordo com Silva (2011, p. 90),

a tradição crítica inicial chamou nossa atenção para as determinações de classe do currículo. $O$ multiculturalismo mostra que o gradiente da desigualdade em matéria de educação e currículo é função de outras dinâmicas, como as de gênero, raça e sexualidade por exemplo, que não podem ser reduzidas à dinâmica de classe.

Ainda na visão do autor, é preciso lançar novos olhares para as diferenças em um mesmo grupo social e por consequência considerá-las no currículo. Nesse sentido, destaca que as teorias pós-críticas, diferentes das teorias críticas que davam ênfase quase que exclusiva nas relações de classe social e no campo das relações econômicas do capitalismo, ampliam nossa compreensão para outros processos de dominação como os que envolvem as "[...] relações de gênero, etnia, raça e sexualidade e nos fornece um mapa muito mais completo e complexo das relações sociais de dominação [...]" (SILVA, 2011, p. 146).

Finalmente, vale destacar o legado e as contribuições de cada teoria uma dessas teorias de currículo apresentadas. Todavia, em uma sociedade plural como a que vivemos, na qual a escola tem se constituído cada vez mais em um espaço inegavelmente multicultural, é preciso contestar os valores, práticas e as manifestações dominantes que insistem em homogeneizar, apagar, ou pelo menos ofuscar as diferenças de modo que 
“[...] não podemos mais olhar o currículo com a mesma inocência de antes (SILVA, 2011, p. 150). Nesse sentido, concordamos com Santomé (2013, p. 9) quando o pesquisador afirma que se comprometer com uma educação verdadeiramente crítica e libertadora nos “[...] obriga a investigar em que medida os objetivos, os conteúdos, os materiais curriculares, as metodologias didáticas e os modelos de organização escolar respeitem as necessidades dos distintos grupos sociais que convivem em cada sociedade".

\section{O campo da educação em direitos humanos}

A concepção contemporânea de direitos humanos está relacionada com a premissa da dignidade humana universal. Tal ideia foi introduzida conforme Piovesan (2006, p. 16), com o advento da Declaração Universal de 1948 e reiterada pela Declaração de Direitos Humanos de Viena de 1993 como "[...] fruto do movimento de internacionalização dos direitos humanos, que constitui um movimento extremamente recente, $[. .$.$] surgindo, a$ partir do pós-guerra, como respostas às atrocidades e os horrores do nazismo".

Conforme a autora, a Declaração de 1948 inovou o conjunto dos direitos humanos ao introduzir a universalidade e indivisibilidade destes direitos. Universalidade "porque clama pela extensão universal dos direitos humanos, sob a crença de que a condição de pessoa é o requisito único para a titularidade de direitos [...]" e indivisibilidade "porque a garantia dos direitos civis e políticos é condição para a observância dos direitos sociais, econômicos e culturais e vice-versa", de modo que, "quando um deles é violado, os demais também o são." (PIOVESAN, 2006, p. 18).

A partir da Declaração de 1948, um progressivo engajamento da comunidade internacional tem ocorrido no sentido de adotar instrumentos legais, visando garantir a efetividade dos direitos humanos nas sociedades contemporâneas. Todavia, apesar dos Tratados Internacionais e das legislações da maioria dos países contemplarem o ideário desses direitos, sua conquista plena depende de um processo formado por um conjunto de atos coordenados e permanentes, de modo a torná-los gerais, comuns e coletivos.

Embora reconheçamos que as conquistas obtidas no universo legal com relação aos direitos humanos sejam importantes e necessárias, entendemos que elas já não satisfazem. É necessário um novo passo, elevar os direitos humanos do plano retórico para uma prática efetiva e, nesse sentido, entendemos que um impulso imprescindível no 
processo de declaração, universalização e efetivação dos direitos humanos é a própria consciência de sua existência por parte de seus sujeitos de direito.

Frente tais considerações, ao assumirmos a escola enquanto lócus privilegiado de um conjunto de atividades que, se corretamente elaboradas e trabalhadas, podem colaborar para o acesso e ampliação da cidadania; destacamos, assim, a importância da educação como instrumento de cidadania e da Educação em Direitos Humanos (EDH) como parte fundamental dessa formação. Concordamos com Silva e Tavares (2013, p. 50), ao defenderem que por intermédio da educação "[...] as pessoas podem tornar-se sujeitos de direitos, conhecedores dos processos e construções históricas das conquistas, avanços e recuos em relação à efetividade e ampliação dos seus direitos e deveres".

Devido sua grande relevância, a cada dia tem se ampliado mais as discussões envolvendo a temática da Educação em Direitos Humanos. Entre os principais esforços da ONU em promover o tema destaca-se o Congresso Internacional sobre Educação em Prol dos Direitos Humanos e da Democracia realizado em março de 1993 na cidade de Viena (AUT), ocasião em que foi instituído o Plano Mundial de Educação em Direitos Humanos (PMEDH).

A Educação em Direitos Humanos recebeu um reconhecimento ainda maior por parte da comunidade internacional com a promulgação da Década da Educação em Direitos Humanos, equivalendo ao período de 1 de janeiro de 1995 a 31 de dezembro de 2004. Na esteira das ações promovidas ao longo desse período e com o objetivo de fomentar o desenvolvimento de programas nacionais voltados para a Educação em Direitos Humanos, a Assembleia Geral das Nações Unidas proclamou, em dezembro de 2004, o Programa Mundial para Educação em Direitos Humanos (Resolução nº 59/113-A).

Voltando-se ao cenário interno do Brasil, a base da construção da agenda dos direitos humanos é bastante tardia e emerge como pauta dos debates políticos e dos programas educacionais apenas no contexto das lutas sociais contra a ditadura militar. Somente após a constituição de 1988 é que os direitos humanos foram realmente assumidos como política de Estado, o que impulsionou a criação de secretarias e programas que buscam materializar a defesa e a promoção dos direitos humanos em todos os níveis de governo. Nessa conjuntura, o compromisso do governo brasileiro com a temática dos direitos humanos foi reafirmado com a criação, em maio de 1996, da primeira 
edição do Programa Nacional de Direitos Humanos (PNDH-1)1. Uma segunda edição foi elaborada em 2002 (PNDH-2)² até que em 2010 chegamos à terceira e mais recente versão, o PNDH-33.

Atendendo às recomendações contidas no Programa Mundial para Educação em Direitos Humanos (PMEDH), o governo brasileiro, por intermédio da Portaria $n^{\circ} 98$ de julho de 2003, criou o Comitê Nacional da Educação em Direitos Humanos, responsável pela produção do Plano Nacional de Educação em Direitos Humanos (PNEDH). Uma primeira versão do PNEDH foi lançada em dezembro daquele ano sendo posteriormente debatida e modificada ao longo dos anos até se chegar a sua versão definitiva em 2007.

Na estrutura e organização, o PNEDH dialoga com o Programa Mundial de Educação em Direitos Humanos e estabelece como áreas prioritárias cinco eixos de atuação considerados fundamentais nesse processo de formação: Educação Básica, Educação superior, Educação não formal, Educação dos Profissionais de Justiça e Segurança e Educação e Mídia (BRASIL, 2007).

A Educação em Direitos Humanos é compreendida de acordo com o PNDEH (BRASIL, 2007, p. 25) "como um processo sistemático e multidimensional que orienta a formação do sujeito de direitos", articulando as seguintes dimensões:

a) apreensão de conhecimentos historicamente construídos sobre direitos humanos e a sua relação com os contextos internacional, nacional e local; b) afirmação de valores, atitudes e práticas sociais que expressem a cultura dos direitos humanos em todos os espaços da sociedade; c) formação de uma consciência cidadã capaz de se fazer presente em níveis cognitivo, social, ético e político; d) desenvolvimento de processos metodológicos participativos e de construção coletiva, utilizando linguagens e materiais didáticos contextualizados; e) fortalecimento de práticas individuais e sociais que gerem ações e instrumentos em favor da promoção, da proteção e da defesa dos direitos humanos, bem como da reparação das violações (BRASIL, 2007, p. 25).

É importante destacar que a Educação em Direitos Humanos, conforme essa compreensão, não se restringe meramente à transmissão de conhecimentos sobre direitos humanos, pelo contrário, trata-se de uma possibilidade de educar para a cidadania priorizando as mudanças de valores, de atitudes e crenças que favoreçam o reconhecimento e valorização das diferenças e das diversidades. Conforme Benevides (2007, p. 346):

\footnotetext{
${ }^{1}$ Decreto Presidencial no 1904 de 13 de maio de 1996 (Revogado pelo Decreto Presidencial nº 4229 de 2002).

${ }^{2}$ Decreto Presidencial $n^{\circ} 4229$ de 13 de maio de 2002. (Revogado pelo Decreto Presidencial $n^{\circ} 7.037$ de 2009).

3 Decreto Presidencial $n^{\circ} 7.177$ de 12 de maio de 2010.
} 
É a formação de uma cultura de respeito à dignidade humana através da promoção e da vivência dos valores da liberdade, da justiça, da igualdade, da solidariedade, da cooperação, da tolerância e da paz. Isso significa criar, influenciar, compartilhar e consolidar mentalidades, costumes, atitudes, hábitos [...] os quais devem se transformar em práticas.

Posteriormente, em cumprimento aos dispositivos legais expressos em documentos nacionais e internacionais dos quais o Brasil é signatário, o Conselho Nacional de Educação aprovou em 2012, por intermédio do Parecer $n^{\circ}$ 8/2012 e da Resolução $n^{\circ}$ 1/2012, as Diretrizes Nacionais para a Educação em Direitos Humanos (DNEDH) ${ }^{4}$. Em seu artigo $2^{\circ}$, esse documento explicita como é compreendida a Educação em Direitos Humanos

Art. 2 - A Educação em Direitos Humanos, um dos eixos fundamentais do direito à educação, refere-se ao uso de concepções e práticas educativas fundadas nos Direitos Humanos e em seus processos de promoção, proteção, defesa e aplicação na vida cotidiana e cidadã de sujeitos de direitos e de responsabilidades individuais e coletivas (BRASIL, 2012).

A formalização de Diretrizes Nacionais para a Educação em direitos humanos representa um avanço no sentido que esse documento torna obrigatória a inserção de conteúdos de Educação em Direitos Humanos na Educação Básica e Superior, ordenando, inclusive, que sejam revistos os Projetos Pedagógicos institucionais e Políticos de todos os cursos do país. Nesse sentido, estabelece que:

Art. $6^{\circ}$ - A Educação em Direitos Humanos, de modo transversal, deverá ser considerada na construção dos Projetos Político-Pedagógicos (PPP); dos Regimentos Escolares; dos Planos de Desenvolvimento Institucionais (PDI); dos Programas Pedagógicos de Curso (PPC) das Instituições de Educação Superior; dos materiais didáticos e pedagógicos; do modelo de ensino, pesquisa e extensão; de gestão, bem como dos diferentes processos de avaliação (BRASIL, 2012).

Conforme o documento das Diretrizes Nacionais para a Educação em Direitos Humanos, os sistemas de ensino e as instituições podem incorporar os conteúdos referentes à Educação em Direitos Humanos de diferentes formas:

Art. $7^{\circ}$ - pela transversalidade, por meio de temas relacionados aos Direitos Humanos e tratados interdisciplinarmente; II - como um conteúdo específico de uma das disciplinas já existentes no currículo escolar; III - de maneira mista, ou seja, combinando transversalidade e disciplinaridade (BRASIL, 2012).

Ao adotar a transversalidade da Educação em Direitos Humanos nas disciplinas e conteúdos, as DNEDH concebem o currículo em uma perspectiva complexa e globalizada, possibilitando o desencadeamento de vivências e experiências significativas que podem

\footnotetext{
${ }_{4}^{4}$ Resolução N 1, DE 30 DE MAIO DE 2012 que estabelece Diretrizes Nacionais para a Educação em Direitos Humanos.
} 
contribuir na formação para a cidadania. Tal perspectiva, ao considerar todos os atores como parte do processo educacional, permite a conexão dos conhecimentos científicos teoricamente sistematizados com as questões da vida real. Nesse sentido, Magendzo (2008, p. 103), destaca que a importância da transversalidade reside no fato que tal proposta para o trabalho,

[...] não se esgotam nas sugestões didáticas propostas em cada unidade, elas tentam ajudar o professor na identificação de outras oportunidades que oferecem conteúdos e materiais educativos para a formação ética cívica. Com estas unidades busca-se fortalecer o contato permanente entre trabalho em sala de aula e a vida diária dos alunos dentro e fora da escola.

Dessa forma, se por um lado, há que se reconhecer a importância da transversalidade ao se abordar questões tão amplas e plurais como as que envolvem a Educação em Direitos Humanos, pois a instituição desses conteúdos em uma disciplina específica, além de por si só não garantir que as propostas do PNEDH e das DNEDH sejam implementadas, também certas resistências poderiam surgir no processo, como é o caso do currículo oculto.

Todavia, por outro lado, considerando que as discussões relacionadas aos direitos humanos muitas vezes tendem a tornar-se conflituosas devido aos diferentes interesses em jogo, vale destacar certos desafios que o tratamento transversal desses conteúdos pode apresentar, pois, como nos lembra Horta (2000, p. 128), “[...] como trabalhar direitos humanos de maneira integrada, a partir de sua relação indissolúvel e interdependente com todos os temas em cuja raiz estão a discriminação, a destruição, a violação e a dominação". Dessa maneira:

É preciso estar disposto a se questionar em que medida a seleção de conteúdos culturais com os quais se trabalha nas salas de aula tem como objetivo fundamental preservar os interesses de determinados grupos hegemônicos e construir relações de poder a seu serviço, em vez de promover aprendizados libertadores em contextos de ensino e aprendizagem democráticos (TORRES SANTOMÉ, 2013, p. 12).

Tomando como base os conceitos anteriormente vistos sobre as teorias de currículo, percebe-se que aquela que melhor possibilitaria uma educação permeada pelos direitos humanos seria a teoria pós-crítica, uma vez que de acordo com Silva (2011, p. 8889) um currículo inspirado nesta concepção “[...] não se limitaria, pois, a ensinar a tolerância e o respeito, por mais desejável que isso possa parecer. [...] Num currículo 
multiculturalista crítico, a diferença, mais que tolerada ou respeitada, é colocada permanentemente em questão".

No tocante à Educação em Direitos Humanos, tais avanços normativos são pistas daquilo que o Brasil vem construindo na defesa de uma sociedade mais democrática, justa e solidária. Por outro lado, não se pode negar a persistência de uma cultura em nosso país, construída e marcada por desigualdades, discriminações, preconceitos e diversas formas de violências, a qual torna cada vez mais difícil a conciliação entre o proclamado em sua legislação e o efetivado na vida da maior parte de sua população.

\section{CONSIDERAÇÕES FINAIS}

São bastante significativos os desafios para a construção de uma sociedade mais democrática e justa conforme propõe a Educação em Direitos Humanos. Isso por que, estamos falando da tentativa de instauração de nova cultura, a qual tem como centro o ser humano e sua dignidade.

Acreditamos que mesmo em um cenário pouco animador como o atual, no qual conforme Torres Santomé (2013, p. 157) “[...] as pessoas têm medo de construir relações duradouras; a solidariedade lhes interessa em função dos benefícios que gera, [...] a construção do comunitário é substituído pela estética do consumo e por relações efêmeras[...]" a Educação em Direitos Humanos pode se constituir numa prática libertadora, transformadora, de uma educação para a cidadania.

Considerando que os valores e conteúdos curriculares incidem na construção de diferentes identidades, um passo fundamental para que a cultura dos direitos humanos possa ser interiorizada pelos estudantes e se converta em ações seria a sua implementação nos currículos educacionais conforme é previsto na legislação brasileira, entretanto, tal prática ainda não tem se concretizado plenamente. Nesse sentido, é preciso se pensar o currículo realmente como campo de disputa, ou seja, avaliar, considerar, investigar se aquilo que tem sido proposto respeita e atende à diversidade de culturas, ideias e ideais dos diferentes sujeitos sociais. 


\section{REFERÊNCIAS}

APPLE, Michel W. A política do conhecimento oficial: faz sentido a ideia de um currículo nacional? In: MOREIRA, Antônio Flavio Barbosa; SILVA, Tomaz Tadeu; Currículo, cultura e sociedade. 6. ed. São Paulo: Cortez, 2002, p. 59 - 91.

BENEVIDES, Maria Victoria. Direitos humanos: desafios para o século XXI. In: SILVEIRA, Rosa Maria Godoy. Educação em direitos humanos: fundamentos teórico-metodológicos. João Pessoa: Universitária, 2007. p. 335-350.

BRASIL. Comitê Nacional de Educação em Direitos Humanos. Plano Nacional de Educação em Direitos Humanos. Brasília, DF: Secretaria Especial dos Direitos Humanos, Ministério da Educação, Ministério da Justiça, UNESCO, 2007. Disponível em: http://portal.mec.gov.br/docman/2191-plano-nacional-pdf/file. Acesso em: 15 abr. 2021.

BRASIL. Ministério da Educação. Conselho Nacional de Educação. Resolução n. 1, de 30 de maio de 2012. Diretrizes Nacionais para a Educação em Direitos Humanos. Diário Oficial União: seção 1, Brasília/DF, n. 105, mai. 2012. p. 48. Disponível em: http://portal.mec.gov.br/conselho-nacional-de-educacao/atosnormativos--sumulasparecer es-e-resolucoes?id=17810. Acesso em: 13 abr. 2021.

EYNG, Ana Maria. Currículo escolar. Curitiba: InterSaberes, 2012.

EYNG, Ana Maria. Educação em direitos humanos no currículo escolar: o projeto políticopedagógico como espaço de garantia ou violação de direitos. In: EYNG, Ana Maria . Direitos humanos e violências nas escolas: desafios e questões em diálogo. Curitiba: CRV, 2013. p. $29-58$

HORTA, Maria Del Mar Rubio. Educar em direitos humanos: compromisso com a vida. In: CANDAU, Vera Maria; SACAVINO, Susana. Educar em direitos humanos: construir democracia. Rio de Janeiro: DP\&A, 2000, p. 125 - 139.

MAGENDZO, Abraham K. La escuela y los derechos humanos. México: Cal y arena, 2008.

MOREIRA, Antônio Flavio Barbosa; SILVA, Tomaz Tadeu. Sociologia e teoria crítica do currículo: uma introdução. In: MOREIRA, Antônio Flavio Barbosa; SILVA, Tomaz Tadeu. Currículo, cultura e sociedade. 6. ed. São Paulo: Cortez, 2002. p. 7-37.

OLIVEIRA, Zélia Maria Freire. Currículo: um instrumento educacional, social e cultural. Revista Diálogo Educacional, Curitiba, v. 8, n. 24, mai./ago. 2008, p. 535-548. Disponível em: https://docplayer.com.br/9818888-Curriculo-um-instrumento-educacional-social-ecultural.html. Acesso em: 21 abr. 2021.

PIOVESAN, Flávia. Direitos humanos. Curitiba: Juruá, 2006.

SILVA, Tomaz Tadeu. Documentos de identidade: uma introdução às teorias do currículo. 3. ed. Belo Horizonte: Autêntica, 2011. 
SILVA, Aida Maria Monteiro; TAVARES, Celma. Educação em direitos humanos no Brasil: contexto, processo de desenvolvimento, conquistas e limites. Revista Eletrônica da Pontifícia Universidade Católica do Rio Grande do Sul, v. 36, n. 1, abr. 2013. p. 50-58. Disponível em: http://revistaseletronicas.pucrs.br/ojs/index.php/faced/article/viewFile/12315/8740. Acesso em: 13 mai. 2021.

TORRES SANTOMÉ, Jurjo. Currículo escolar e justiça social: o cavalo de tróia da educação. Tradução: Alexandre Salvaterra. Porto Alegre: Penso, 2013.

ZENAIDE, Maria de Nazaré Tavares. Introdução. In: SILVEIRA, Maria Godoy. Educação em direitos humanos: fundamentos teóricos metodológicos. João Pessoa: Editora Universitária UFJP, 2007. p. 15-24.

Recebido em: 30/04/2021

Parecer em: 27/05/2021 Aprovado em: 07/06/2021 